Check for updates

Cite this: Chem. Sci., 2019, 10, 8195

๑ All publication charges for this article have been paid for by the Royal Society of Chemistry

Received 22nd March 2019

Accepted 22nd July 2019

DOI: $10.1039 / c 9 s c 01415 b$

rsc.li/chemical-science

\section{Facile synthesis of supported Ru-Triphos catalysts for continuous flow application in selective nitrile reduction $\uparrow$}

\author{
Robert Konrath, (D) ${ }^{\text {ab }}$ Frank J. L. Heutz, ${ }^{a}$ Norbert Steinfeldt, ${ }^{b}$ Nils Rockstroh (D) ${ }^{b}$ \\ and Paul C. J. Kamer (D)*b
}

\begin{abstract}
The selective catalytic hydrogenation of nitriles represents an important but challenging transformation for many homogeneous and heterogeneous catalysts. Herein, we report the efficient and modular solid-phase synthesis of immobilized Triphos-type ligands in very high yields, involving only minimal work-up procedures. The corresponding supported ruthenium-Triphos catalysts are tested in the hydrogenation of various nitriles. Under mild conditions and without the requirement of additives, the tunable supported catalyst library provides selective access to both primary amines and secondary imines. Moreover, the first application of a Triphos-type catalyst in a continuous flow process is presented demonstrating high catalyst life-time over at least 195 hours without significant activity loss.
\end{abstract}

\section{Introduction}

Amines represent essential platform chemicals pivotal for industrial synthesis of both bulk and fine chemicals as well as for pharmaceuticals. ${ }^{1-3}$ Common methods towards the catalytic production of primary amines include amination of alcohols, ${ }^{4}$ reductive amination, ${ }^{5}$ and reduction of nitro compounds ${ }^{6-9}$ and amides. ${ }^{10,11}$ Atom-economical hydrogenation of nitriles using inexpensive molecular hydrogen can offer an alternative route to primary amines. While conventional but less benign procedures often use stoichiometric amounts of metal hydrides, heterogeneous catalysts are widely applied in manufacture of bulk chemicals, e.g. reduction of adiponitrile to hexamethylenediamine in the production of nylon- $66 . .^{12}$ Heterogeneous catalysts are commonly based on noble (Pd) or base metals (RANEY®-Ni, Co and iron), which often suffer from reduced selectivity combined with low functional group tolerance. ${ }^{13-16}$ Base metals usually require harsh conditions and the use of additives, such as ammonia and mineral acids, to suppress side reactions. ${ }^{13,17}$ Milder reaction conditions can be applied when utilizing supported Pd catalysts, however, these are still reliant on acidic conditions to produce the terminal amines selectively. ${ }^{18-20}$ On the other hand, there has been a growing interest to develop highly selective homogeneous catalysts for applications in nitrile reduction under very mild conditions. Most

${ }^{a}$ School of Chemistry, University of St Andrews, North Haugh, St Andrews, Fife, KY16 9ST,UK. E-mail: rk49@st-andrews.ac.uk

${ }^{b}$ Leibniz-Institut für Katalyse e. V. an der Universität Rostock, Albert-Einstein Straße 29a, 18059 Rostock, Germany.E-mail: Paul.Kamer@catalysis.de

$\dagger$ Electronic supplementary information (ESI) available: Experimental section, characterization, continuous flow optimization. See DOI: 10.1039/c9sc01415b transition-metal complexes are based on precious metals featuring well-defined ligand structures, ${ }^{17,21,22}$ but more recently also base metals ${ }^{23,24}$ have been employed. Tripodal phosphorusbased ligands, such as Triphos (Fig. 1, I), remain less studied in nitrile reduction despite their successful application in hydrogenations of challenging carboxylic acids derivatives. ${ }^{25-29}$ Initial attempts by Suarez and Fontal using a Ru-Triphos system in pure benzonitrile led to an unselective mixture of amines. ${ }^{30}$ Beller and co-workers reported on the tripodal phosphorus ligand II employed in Ru-catalyzed nitrile hydrogenation achieving high selectivities for a range of aliphatic and aromatic monoamines under mild and additive-free conditions, ${ }^{31}$ whereas no activity in this reaction was observed for a cobaltTriphos catalyst. ${ }^{32}$

Moreover, the intrinsic separation issue of homogeneous catalysts remains a limiting factor for many applications. ${ }^{35}$ To

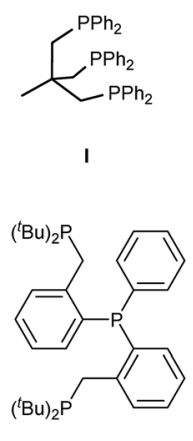

II

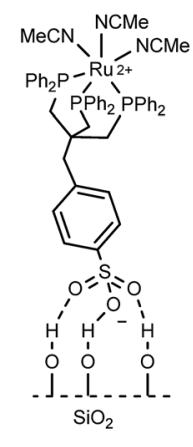

III

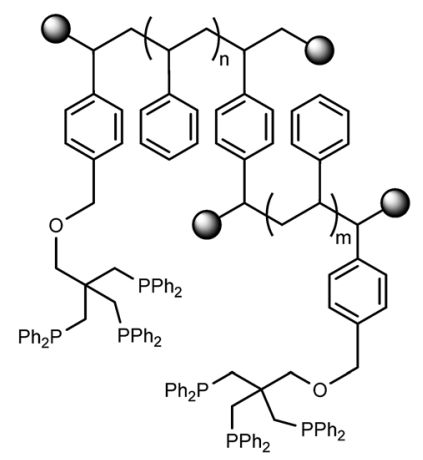

IV
Fig. 1 Tripodal ligands I and II ${ }^{31}$ and examples of immobilized Triphos on silica (III) ${ }^{33}$ and polystyrene (IV). ${ }^{34}$ 
overcome this problem a tremendous research effort has been devoted to heterogenization of molecular catalysts. ${ }^{35-41}$ Thus, the ideal catalyst would combine the best of both worlds, i.e. high activity, selectivity and tunability of homogeneous catalysis and the ease of separation and recycling of heterogeneous catalysts. The enhanced stability of supported tridentate ligandbased catalysts compared to mono- and bidentate analogues can prevent metal leaching from the support. Approaches towards immobilization of modified Triphos ligands on dendrimers, ${ }^{42}$ in ionic liquids ${ }^{43}$ and in aqueous biphasic systems ${ }^{\mathbf{4 4 - 4 6}}$ have been explored. Furthermore, $\mathrm{SiO}_{2}$ grafted $\mathrm{Ru}-$ Triphos (Fig. 1, III) has been applied in the reduction of benzonitrile to the corresponding secondary imine. ${ }^{33}$ Immobilization of Triphos onto polymeric supports was accomplished by a following post-modification ${ }^{47}$ as well as a bottom-up approach (Fig. 1, IV). ${ }^{34}$ However, all of the above mentioned strategies are cases where a single modified ligand is tethered to a support. Often these synthetic alterations require multiple steps and can lead to low yields due to troublesome purifications or functional group incompatibility which in turn hampers the creation of ligand diversity on the support. ${ }^{48}$ Moreover, tuning ligand properties by modifying the phosphorus donor moieties remains challenging. Opposed to the uncomplicated synthesis of $C_{3 \mathrm{~V}}$ symmetrical arylphosphine tripods, ${ }^{49}$ unsymmetrical, mixed phosphorus donor ligands rely on less straightforward synthetic protocols. ${ }^{50-52}$ Different leaving groups bound to the tripodal backbone to facilitate selective phosphine substitution as well as additional borane protection and removal steps are often necessary. In case of a $C_{1}$ symmetric Triphos analogue modified with one di( $p$-tolyl)phosphine and two $\mathrm{PPh}_{2}$ groups an overall yield of $21 \%$ starting from 3-methyl-3-oxetanemethanol was obtained. ${ }^{52}$ This in turn calls for a more efficient modular approach. Solid-phase synthesis (SPS) provides a promising alternative offering the combinatorial synthesis of libraries of tripodal ligands on a support in high yields requiring only minimal workup procedures. ${ }^{53-55}$ Moreover, SPS has proven to be an invaluable tool for automated parallel synthesis of ligand libraries in terms of application in high throughput experimentation. ${ }^{56-58}$ Since covalently bound to the support, recycling of the corresponding heterogenized catalysts can be vastly facilitated making them suitable candidates for application in continuous flow catalysis. Continuous processes allow exploring the long-term catalyst performance but also offer environmentally benign and safe processing, facile optimization for scale-up and high process reliability for multiphasic hydrogenation reactions, which in general are a prerequisite for economical process development. ${ }^{\text {9-61 }}$ Herein, we report a modular SPS protocol towards recyclable $\mathrm{Ru}$-Triphos complexes and their application in highly selective nitrile reduction. Furthermore, the first application of Triphos-based ligands under continuous flow processing is presented.

\section{Results and discussion}

\section{Solid-phase synthesis of supported Triphos ligands}

The SPS of supported tripodal phosphorus ligands was adapted from literature procedures in solution-phase. ${ }^{51,62}$ The secondary phosphines 1a-d immobilized on Merrifield resin cross-linked with $1 \%$ and $4 \%$ divinylbenzene (DVB, MF), JandaJel ${ }^{\mathrm{TM}}$ resin (JJ) and polystyrene (PS) were prepared as we reported previously.$^{\mathbf{6 3 , 6 4}}$ Deprotonation of 1a-d by using an excess of lithium diisopropylamide (LDA) yielded the corresponding supported lithium phosphides (Scheme 1, step 1).

In the gel-phase ${ }^{31} \mathrm{P}$ NMR spectrum, phenyl substituted lithiated phosphines $(\mathbf{L i} \cdot \mathbf{1 a}-\mathbf{c})$ exhibit signals at $\delta=-40 \mathrm{ppm}$ (see Fig. 2 for a representative example), while for ${ }^{t} \mathrm{Bu}$ bearing lithium phosphide $\mathbf{L i} \cdot \mathbf{1 d}$ supported on PS a shift of around $\Delta \delta$ $=7 \mathrm{ppm}$ is observed. Next, $\mathbf{L i} \cdot \mathbf{1 a}-\mathbf{d}$ were reacted at room temperature with a slight excess of 1,1,1-tris(chloromethyl) ethane readily proceeding to the supported phosphine dimethylenechloride intermediates 2a-d (Scheme 1, step 2). Quantitative conversion was confirmed by ${ }^{31} \mathrm{P}$ NMR by the appearance of a single peak at around $\delta=-30 \mathrm{ppm}$ in cases of $\mathbf{2 a - c}$ and $\delta=-11.4 \mathrm{ppm}$ for $\mathbf{2 d}$ respectively. High purity of representative compound $2 \mathbf{a}$ was confirmed by determination of the $\mathrm{P}$ and $\mathrm{Cl}$ loading by elemental analysis. Subsequently, intermediates 2a-d were treated with a secondary lithium phosphide to obtain the desired supported Triphos ligands $\mathbf{L}_{\mathbf{1}}-$ $\mathbf{L}_{5}$. By using an excess of $\mathrm{LiPPh}_{2}\left(\right.$ for $\left.\mathbf{L}_{\mathbf{1}}-\mathbf{L}_{\mathbf{4}}\right)$ or $\operatorname{LiP}(o-\mathrm{Tol})_{2}\left(\right.$ for $\left.\mathbf{L}_{5}\right)$ at $60{ }^{\circ} \mathrm{C}$, full conversions to the corresponding ligands were achieved leading to a library of 5 supported Triphos-type ligands (Scheme 1, step 3).

The Triphos analogue $\mathbf{L}_{\mathbf{1}}$ supported on MF exhibits two single peaks $(\delta=-25.4$ and $-28.1 \mathrm{ppm})$ in the ${ }^{31} \mathrm{P}$ NMR spectrum, occurring in a $2: 1$ ratio (Fig. 2). For JJ-supported ligand $\mathbf{L}_{2}$ as well as $\mathbf{L}_{3}$ immobilized on the MF $4 \%$ DVB, nearly identical spectra were obtained. In case of PS supported $\mathbf{L}_{\mathbf{4}}$, two peaks were observed for the $\mathrm{PPh}_{2}$ groups $(\delta=-25.0$ and $-25.8 \mathrm{ppm})$ which are present in an approximate ratio of $1: 1: 1$ with the $\mathrm{P}^{t} \mathrm{Bu}$ moiety $(\delta=-8.8 \mathrm{ppm})$. This could be attributed to the presence of the bulky ${ }^{t} \mathrm{Bu}$ group leading to sterically hindered rotation which allows for the detection of the two inequivalent diastereotopic phosphorus nuclei on the NMR time scale. Similarly, $\mathbf{L}_{\mathbf{5}}$ shows a signal for the PPh group $(\delta=-28.3 \mathrm{ppm})$ together with two signals for the diastereotopic $\mathrm{P}(o \text {-Tol })_{2}$ moieties $(\delta=-51.9$ and $-52.0 \mathrm{ppm})$. The supported tripodal ligands $\mathbf{L}_{\mathbf{1}}-\mathbf{L}_{\mathbf{5}}$ were further characterized using FTIR and Raman spectroscopy and the exact phosphorus loading was determined by elemental analysis (see ESI $\dagger$ ).

\section{Solid-phase synthesis of supported ruthenium complexes}

The corresponding immobilized $\mathrm{Ru}$-Triphos complexes $\mathbf{C}_{\mathbf{1}}-\mathbf{C}_{\mathbf{5}}$ were synthesized by treatment of $\mathbf{L}_{\mathbf{1}}-\mathbf{L}_{\mathbf{5}}$ with $\left[\mathrm{RuHCl}\left(\mathrm{PPh}_{3}\right)_{3} \mathrm{CO}\right]$ in toluene at $80{ }^{\circ} \mathrm{C}$ (Scheme 2).

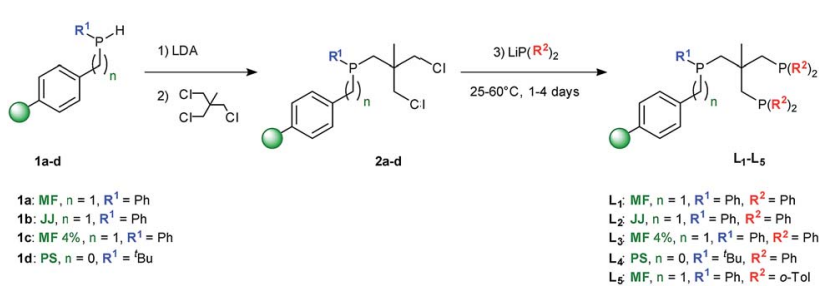

Scheme 1 SPS approach towards supported Triphos ligands $L_{1}-L_{5}$. 


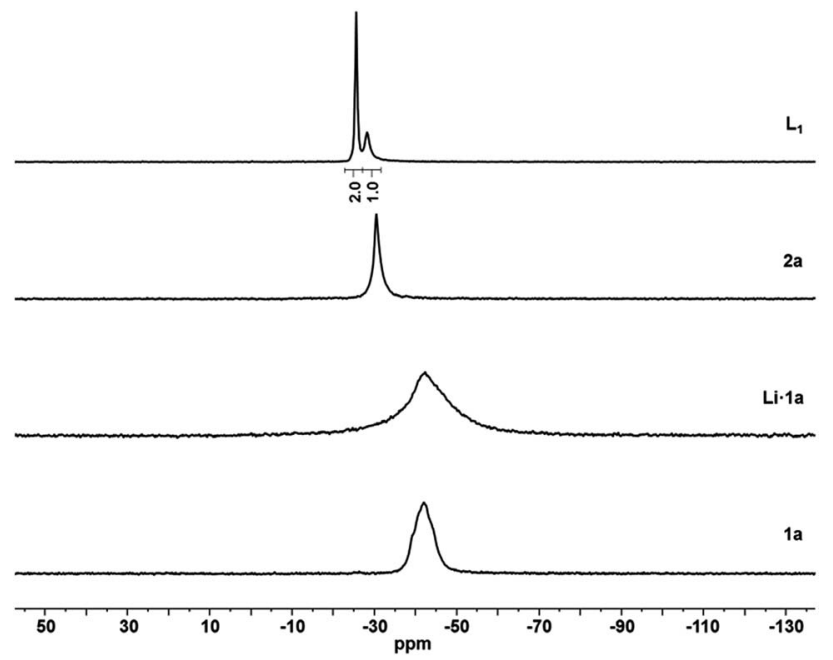

Fig. $2{ }^{31} \mathrm{P}$ NMR (THF) monitoring of the representative SPS of supported Triphos-ligand $\mathrm{L}_{1}$.

The quantitative disappearance of the free ligand peaks was monitored by ${ }^{31} \mathrm{P}$ NMR until full complexation was achieved. $\mathbf{C}_{\mathbf{1}}$ shows three new broad signals appearing in an approximate $1: 1: 1$ ratio (Fig. 3). While two sharper single resonances are observed at $\delta=15.3$ and $1.2 \mathrm{ppm}$ for the remote $\mathrm{PPh}_{2}$ moieties, the broader signal of the phosphorus atom bound to the polymeric support exhibits a splitting $(\delta=49.8$ and $41.8 \mathrm{ppm})$ which could be attributed to the presence of isomeric $\mathrm{Ru}$ complexes as observed in non-symmetrical homogeneous systems. ${ }^{52}$ The gel-phase ${ }^{31} \mathrm{P}$ NMR of JandaJel ${ }^{\mathrm{TM}}$-supported complex $\mathbf{C}_{2}$ shows an analogous spectrum compared to $\mathbf{C}_{\mathbf{1}}$ (Fig. S13, see ESI $\dagger$ ). In this case however, much sharper signals are observed as a consequence of enhanced solution-like behavior of the JJ resin. Coupling constants cannot be assigned due to peak broadening which is commonly observed for molecular complexes heterogenized on solid supports. ${ }^{34,63,65,66}$ However, the chemical shifts of $\mathbf{C}_{\mathbf{1}}$ are in line with those obtained for its solution-phase counterpart $3(\delta=$ 48.9, 12.2 and -0.4 ppm, Fig. 4a). 3 solely differs in a Ph group attached to the phosphorus atom instead of a benzyl group belonging to the MF support. Moreover, the supported complexes were characterized by solid-state ${ }^{31} \mathrm{P},{ }^{1} \mathrm{H}$ and ${ }^{13} \mathrm{C}$ MAS NMR. In the case of $\mathbf{C}_{\boldsymbol{1}}$, the ${ }^{31} \mathrm{P}$ MAS NMR spectrum exhibits two signals appearing in a $1: 2$ ratio (Fig. 4c). The presence of a $\mathrm{CO}$ ligand and $\mathrm{Ru}-\mathrm{H}$ was confirmed by FTIR and Raman spectroscopy (see ESI $\dagger$ ). For $\mathrm{CO}$ and $\mathrm{Ru}-\mathrm{H}$, bands are observed at $1975-1968 \mathrm{~cm}^{-1}$ and $1925-1920 \mathrm{~cm}^{-1}$, respectively.

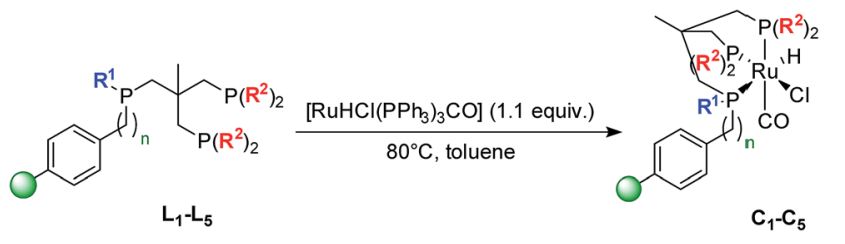

Scheme 2 Synthesis of supported complexes $C_{1}-C_{5}$.

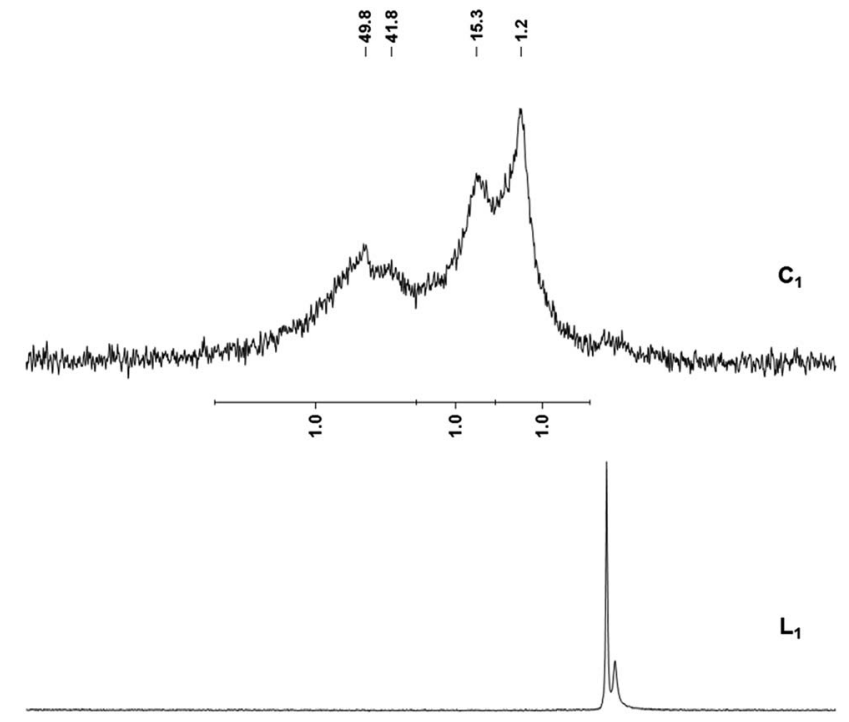

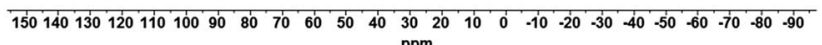

Fig. $3{ }^{31} \mathrm{P}$ NMR (THF) monitoring of the representative SPS of supported Ru-Triphos complex $\mathrm{C}_{1}$.

\section{Application in Ru-catalyzed nitrile reduction}

Subsequently, the supported Ru-Triphos library was screened in the hydrogenation of nitriles to primary mono- and diamines. Prior to catalyst screening, benzonitrile $\left(\mathbf{S}_{\mathbf{1}}\right)$ and $\mathbf{C}_{\mathbf{1}}$ were used to determine optimized reaction conditions. 1,4Dioxane was chosen as solvent providing sufficient polymer swelling properties opposed to ${ }^{i} \mathrm{PrOH}$, which was found to be the ideal solvent in homogeneous Ru-Triphos catalyzed nitrile

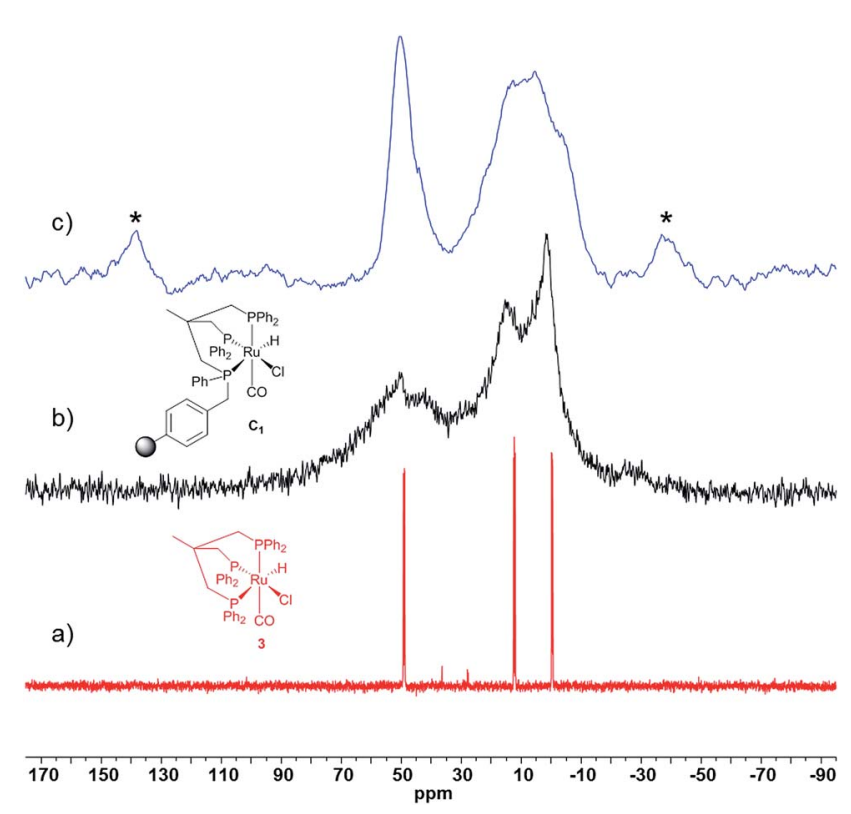

Fig. 4 (a) ${ }^{31}$ P NMR spectrum of solution-phase analogue 3, (b) gelphase ${ }^{31}$ P NMR spectrum of supported complex $C_{1}$ and (c) solid-state ${ }^{31} \mathrm{P}$ MAS NMR spectrum of $\mathrm{C}_{1}$. Rotational sidebands are denoted by asterisks (*). 
reduction. ${ }^{31}$ After $18 \mathrm{~h}$ at 10 bar $\mathrm{H}_{2}$ pressure and $100{ }^{\circ} \mathrm{C}, \mathbf{S}_{\mathbf{1}}$ was readily converted with excellent selectivity towards the desired benzylamine (A) using $1.0 \mathrm{~mol} \%$ of $\mathbf{C}_{\mathbf{1}}$ (Table 1, entry 1). A similar performance was obtained when reducing the temperature to $80{ }^{\circ} \mathrm{C}$ (Table 1, entry 2) whereas $0.5 \mathrm{~mol} \%$ gave $47 \%$ conversion with $97 \%$ selectivity to A (Table 1 , entry 3 ). Further optimization conditions are listed in Table S1. $\dagger$ For selectivity enhancement towards the primary amine, both homogeneous and heterogeneous catalysts often require the use of base additives. ${ }^{13,18-20,67,68}$ Remarkably, mild and additive-free conditions can be applied for this highly selective heterogeneous $\mathrm{Ru}-$ Triphos system similar to the homogeneous system of Beller and co-workers. ${ }^{31}$ When screening the whole supported catalyst library at $100{ }^{\circ} \mathrm{C}$ and $1.0 \mathrm{~mol} \%$ catalyst loading, JJ-supported $\mathbf{C}_{2}$ and PS-bound $\mathbf{C}_{\mathbf{4}}$ performed analogously compared to $\mathbf{C}_{\mathbf{1}}$ (Table 1, entries 4 and 6). Notably, $\mathrm{C}_{3}$ immobilized on $\mathrm{MF} 4 \% \mathrm{DVB}$, which is lacking solvent dependent swelling properties opposed to $C_{1}$, gave $62 \%$ conversion and $97 \%$ selectivity (Table 1 , entry 5 ) which could be driven to full conversion after $50 \mathrm{~h}$.

Unexpectedly, $\mathbf{C}_{5}$ bearing more bulky $\mathrm{P}(o-\mathrm{Tol})_{2}$ groups resulted in $86 \%$ conversion with $92 \%$ selectivity towards the secondary imine $\mathbf{B}$ (Table 1, entry 7 ) which could be increased to $>99 \%$ selectivity at $56 \%$ conversion after 8 hours (Table S1, $\dagger$ entry 10). In case of the solution-phase combination of $\left[\mathrm{Ru}(\operatorname{cod})(\text { methallyl })_{2}\right]$ (cod = cyclooctadiene) and II, no activity was observed when using 1,4-dioxane as a solvent. ${ }^{31}$ When applying homogeneous catalyst $\mathbf{3}$ under the same conditions as for its supported counterparts, an unselective mixture of $\mathbf{A}$ (30\%), B (68\%) and C (2\%) was obtained (Table 1, entry 8). The superior selectivity of the developed heterogeneous catalyst can be attributed to the high local catalyst to substrate concentration within the confined space of a resin bead suppressing noncatalytic side-reactions. Moreover, the $\mathrm{SiO}_{2}$ supported system III

Table 1 Ru-catalyzed hydrogenation of $S_{1}$ using supported catalysts $\mathrm{C}_{1}-\mathrm{C}_{5}{ }^{a}$

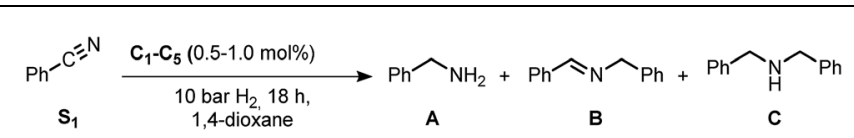

\begin{tabular}{llllllll}
\hline & & & & & \multicolumn{3}{c}{ Selectivity $^{b}[\%]$} \\
\cline { 6 - 8 } Entry & Catalyst $[\mathrm{mol} \%]$ & $T\left[{ }^{\circ} \mathrm{C}\right]$ & Conv. $^{b}[\%]$ & $\mathbf{A}$ & $\mathbf{B}$ & $\mathbf{C}$ \\
\hline 1 & $\mathbf{C}_{\mathbf{1}}(1.0)$ & 100 & $>99$ & 99 & 1 & $<1$ \\
2 & $\mathbf{C}_{\mathbf{1}}(1.0)$ & 80 & $>99$ & 98 & 1 & $<1$ \\
3 & $\mathbf{C}_{\mathbf{1}}(0.5)$ & 80 & 48 & 97 & 3 & $<1$ \\
4 & $\mathbf{C}_{\mathbf{2}}(1.0)$ & 100 & $>99$ & 99 & 1 & $<1$ \\
5 & $\mathbf{C}_{\mathbf{3}}(1.0)$ & 100 & 62 & 97 & 3 & $<1$ \\
6 & $\mathbf{C}_{\mathbf{4}}(1.0)$ & 100 & $>99$ & 99 & 1 & $<1$ \\
7 & $\mathbf{C}_{\mathbf{5}}(1.0)$ & 100 & 86 & 5 & 92 & 2 \\
8 & $\mathbf{3}(1.0)$ & 100 & $>99$ & 30 & 68 & 2 \\
$9^{c}$ & III $(0.2)$ & 100 & 95 & 3 & 88 & 5
\end{tabular}

${ }^{a}$ Conditions: substrate $(0.5 \mathrm{mmol})$, dioxane $(1.0 \mathrm{~mL}), \mathrm{H}_{2}(10 \mathrm{bar}), 18 \mathrm{~h}$. ${ }^{b}$ Conversion and selectivity determined by GC using dodecane as internal standard. ${ }^{c}$ Data taken from ref. 33; conditions: substrate ( $2.15 \mathrm{mmol}), n$-octane $(30 \mathrm{~mL}), \mathrm{H}_{2}$ (30 bar), $12 \mathrm{~h}$.
(Fig. 1) gave $88 \%$ selectivity towards $\mathbf{B}$ instead of $\mathbf{A}$ (Table 1, entry 9). ${ }^{33}$ This showcases both the competitively high selectivity towards primary amines and the facile tunability of the resinbound Triphos using SPS. Next, $\mathbf{C}_{\mathbf{1}}$ was employed to determine the substrate scope. Electron-withdrawing para-bromo $\left(\mathbf{S}_{2}\right)$ and para-fluoro-benzonitrile $\left(\mathbf{S}_{3}\right)$ were converted selectively whereas $\mathrm{NO}_{2}$-substituted $\mathbf{S}_{\mathbf{4}}$ led to no activity accompanied by the formation of ruthenium black as observed in homogeneous deaminative nitrile hydrogenation to primary alcohols (Fig. 5). ${ }^{69}$ This may be attributed to phosphine oxidation followed by deposition of the metal. More electron-donating para-methoxy groups $\left(\mathbf{S}_{5}\right)$ resulted in $79 \%$ conversion and $97 \%$ selectivity. Methyl substituents in ortho-position $\left(\mathbf{S}_{\mathbf{6}}\right)$ proved to be more challenging with only $45 \%$ conversion but with excellent selectivity. At $120{ }^{\circ} \mathrm{C}, \mathbf{S}_{7}$ bearing an ortho-methoxy group was fully converted with $79 \%$ selectivity. Finally, the 1,3-disubstituted benzonitrile $\mathbf{S}_{\mathbf{8}}$ was quantitatively converted into the corresponding diamine after $24 \mathrm{~h}$ at $100{ }^{\circ} \mathrm{C}$ and 30 bar of $\mathrm{H}_{2}$. Aliphatic cyclohexanecarbonitrile $\left(\mathbf{S}_{\mathbf{9}}\right)$ gave $46 \%$ conversion with high selectivity at $120{ }^{\circ} \mathrm{C}$. Heptanenitrile $\left(\mathbf{S}_{\mathbf{1 0}}\right)$ was fully converted with $87 \%$ selectivity to heptylamine. Mainly partial hydrogenation of adiponitrile $\left(\mathbf{S}_{\mathbf{1 1}}\right)$ was observed with $92 \%$ selectivity to $\omega$-aminocapronitrile which can serve as a precursor for the synthesis of nylon- $6 .{ }^{70}$ Benzylic nitriles were selectively hydrogenated with excellent to moderate conversions (99\% for $\mathbf{S}_{\mathbf{1 2}}$ and $72 \%$ for $\mathbf{S}_{\mathbf{1 3}}$ ).

Finally, the recyclability of the resin-bound catalyst $\mathbf{C}_{\mathbf{1}}$ was examined. However, under batch conditions, a loss in activity was observed after the fourth run due to mechanical abrasion of the support (Table S $\uparrow \dagger$ ). Hence, the novel supported catalyst was employed in continuous flow hydrogenation to determine the long-term catalyst performance. The system was initially studied under various flow rates, temperatures and pressures reaching up to $84 \%$ selectivity towards the primary amine A with

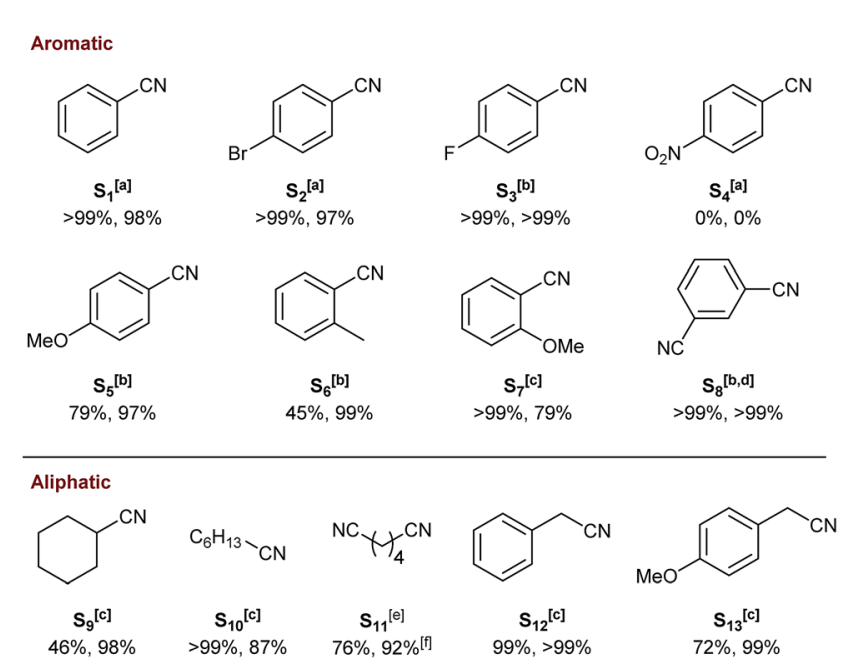

Fig. 5 Substrate scope using supported catalyst $C_{1}$ (conversion and selectivity to mono- or diamine indicated below structures). ${ }^{a}$ Reaction conditions: substrate $(0.5 \mathrm{mmol}),[\mathrm{Ru}](1.0 \mathrm{~mol} \%)$, dioxane $(1.0 \mathrm{~mL})$, $80^{\circ} \mathrm{C}, \mathrm{H}_{2}\left(10\right.$ bar), $18 \mathrm{~h} .{ }^{\mathrm{b}} 100^{\circ} \mathrm{C}$. ${ }^{\mathrm{c}} 120^{\circ} \mathrm{C} .{ }^{\mathrm{d}} \mathrm{H}_{2}$ (30 bar). $24 \mathrm{~h},{ }^{\mathrm{e}} 100{ }^{\circ} \mathrm{C}, \mathrm{H}_{2}$ (30 bar), $24 \mathrm{~h}$. 'Selectivity towards $\omega$-aminocapronitrile. 
full conversion at $150{ }^{\circ} \mathrm{C}$ (Table S3, Fig. S2 $\dagger$ ). While the secondary imine B was observed as the sole by-product, increasing amounts of secondary amine $\mathbf{C}$ formed when exceeding a process temperature of $120{ }^{\circ} \mathrm{C}$.

Next, constant conditions of $100{ }^{\circ} \mathrm{C}$ and 20 bar pressure at a flow rate of $0.1 \mathrm{~mL} \min ^{-1}$ were chosen to provide moderate conversion and selectivity to enable monitoring of actual catalyst stability during the flow experiment. An initial incubation time followed by an increase in activity and selectivity were observed attaining a steady conversion (75\%) and selectivity towards A (60\%) after $100 \mathrm{~h}$ (Fig. 6). This could be attributed to the slow formation of the potentially active Ru-hydrido species analogous to the $\left[\mathrm{Ru}(\mathrm{cod})(\text { methallyl })_{2}\right] /$ II system reported by the group of Beller. ${ }^{31}$ Hence, pre-activation of the supported catalyst $\mathbf{C}_{\mathbf{1}}$ with $\mathrm{H}_{2}$ or the addition of base to the feed could possibly diminish this activation period. In addition to $\mathbf{A}$, the product mixture contained $40 \%$ of secondary imine $\mathrm{B}$ and $0.5 \%$ of secondary amine $\mathbf{C}$ after $100 \mathrm{~h}$ time-on-stream (TOS). The amount of $\mathbf{C}$ remained constant throughout the experiment. The difference in selectivity compared to the batch process is a consequence of the presence of the higher concentration of the imine intermediate resulting from the low conversion level (75\%) needed to monitor catalyst stability. Conversion of the imine intermediate to the primary amine is prevented once the imine has left the catalyst bed.

Replacing the feed solution after $100 \mathrm{~h}$ caused a flow outage for $1 \mathrm{~h}$ followed by an activity increase of the catalyst to nearly full conversion requiring a subsequent restabilization period. Steady conversion (86\%) and selectivity towards benzylamine A (65\%) were recovered after $171 \mathrm{~h}$ followed by a small drop in activity (3\%) within the next $24 \mathrm{~h}$. Over $195 \mathrm{~h}$ TOS, a remarkable catalyst life-time and a total TON of 1605 were achieved together with no $\mathrm{Ru}$ metal contamination observed in the product stream indicated by ICP-OES analysis.

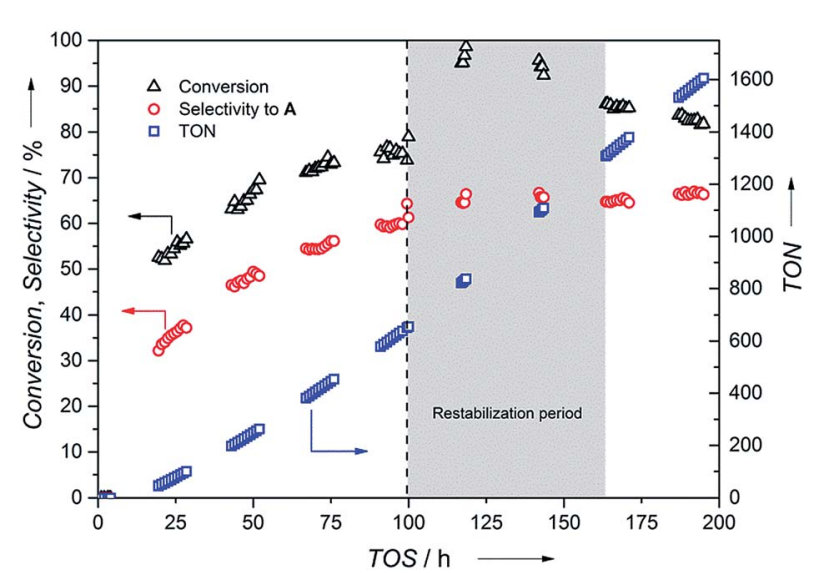

Fig. 6 Continuous flow hydrogenation of $S_{1}$ using $C_{1}$. Conditions: $n_{\text {cat }}$ $=0.134 \mathrm{mmol}, T=100{ }^{\circ} \mathrm{C}, 20$ bar, $0.25 \mathrm{M} \mathrm{S}_{1}$ in dioxane at 0.1

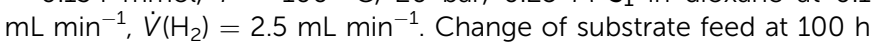
caused malfunctioning of HPLC pump for $1 \mathrm{~h}$ (dashed line). Grey area indicates catalyst restabilization period. Conversion determined by GC using dodecane as internal standard. Selectivity is reported towards formation of primary amine $\mathrm{A}$.

\section{Conclusions}

In summary, we developed an efficient and modular solid-phase synthesis protocol to access diverse supported Triphos-type ligands $\left(\mathbf{L}_{\mathbf{1}}-\mathbf{L}_{\mathbf{5}}\right)$ and their corresponding Ru-complexes $\left(\mathbf{C}_{\mathbf{1}}-\mathbf{C}_{\mathbf{5}}\right)$ requiring only minimal work-up steps. The solid phase approach opens the way to automated synthesis of large ligand libraries enabling a fine-tuned design of catalysts that allow transformations with high selectivity. The library was successfully applied in highly selective nitrile reduction under mild conditions in the absence of any performance enhancing additive as reported for many monophasic and heterogeneously catalyzed liquid/solid reactions. Opposed to homogeneous counterparts, the robust heterogeneous system provided highly selective access to both primary amines and secondary imines due to the modular and hence easily tunable ligand structure. Moreover, a novel Triphos-type catalyst was applied for the first time in a continuous flow process proving high catalyst stability without significant loss in performance for at least 195 hours. Screening of conditions leading to a shorter catalyst incubation time is currently ongoing.

\section{Conflicts of interest}

There are no conflicts to declare.

\section{Acknowledgements}

Financial support for this work was provided by the University of St Andrews, the Engineering and Physical Sciences Research Council (Award Reference 1658187) and the European Union (Marie Curie ITN SusPhos, Grant Agreement No. 317404). We thank A. Simmula for ICP- OES analysis and Dr D. M. Dawson for solid-state NMR measurements.

\section{Notes and references}

1 B. R. Brown, The organic chemistry of aliphatic nitrogen compounds, Oxford University, New York, 1994.

2 S. A. Lawrence, Amines: Synthesis, Properties and Applications, Cambridge University Press, Cambridge, 2004.

3 P. Roose, K. Eller, E. Henkes, R. Rossbacher and H. Höke, in Amines, Aliphatic: Ullmann's Encyclopedia of Industrial Chemistry, Wiley-VCH, Weinheim, 2015.

4 S. Bähn, S. Imm, L. Neubert, M. Zhang, H. Neumann and M. Beller, ChemCatChem, 2011, 3, 1853-1864.

5 S. Gomez, J. A. Peters and T. Maschmeyer, Adv. Synth. Catal., 2002, 344, 1037-1057.

6 A. M. Tafesh and J. Weiguny, Chem. Rev., 1996, 96, 20352052.

7 P. Loos, H. Alex, J. Hassfeld, K. Lovis, J. Platzek, N. Steinfeldt and S. Hübner, Org. Process Res. Dev., 2015, 20, 452-464.

8 M. Orlandi, D. Brenna, R. Harms, S. Jost and M. Benaglia, Org. Process Res. Dev., 2018, 22, 430-445.

9 D. Formenti, F. Ferretti, F. K. Scharnagl and M. Beller, Chem. Rev., 2019, 119, 2611-2680. 
10 A. A. N. Magro, G. R. Eastham and D. J. Cole-Hamilton, Chem. Commun., 2007, 3154-3156.

11 E. Balaraman, B. Gnanaprakasam, L. J. W. Shimon and D. Milstein, J. Am. Chem. Soc., 2010, 132, 16756-16758.

12 B. D. Herzog and R. A. Smiley, in Hexamethylenediamine: Ullmann's Encyclopedia of Industrial Chemistry, Wiley-VCH, Weinheim, Germany, 2012.

13 S. Nishimura, in Handbook of Heterogeneous Catalytic Hydrogenation for Organic Synthesis, John Wiley \& Sons, New York, 2001, ch. 7, pp. 254-285.

14 T. G. Dewdney, D. A. Dowden, B. D. Hawkins and M. Wyndham, Ger. Offen., DE 2429293 A1 19750320, 1975.

15 A. F. Elsasser, WO98/19991, 1998.

16 P. Kukula, M. Studer and H.-U. Blaser, Adv. Synth. Catal., 2004, 346, 1487-1493.

17 C. de Bellefon and P. Fouilloux, Catal. Rev., 1994, 36, 459506.

18 L. Hegedüs and T. Máthé, Appl. Catal., A, 2005, 296, 209-215. 19 Y. Saito, H. Ishitani, M. Ueno and S. Kobayashi, ChemistryOpen, 2017, 6, 211-215.

20 M. Yoshimura, A. Komatsu, M. Niimura, Y. Takagi, T. Takahashi, S. Ueda, T. Ichikawa, Y. Kobayashi, H. Okami, T. Hattori, Y. Sawama, Y. Monguchi and H. Sajiki, Adv. Synth. Catal., 2018, 360, 1726-1732.

21 D. B. Bagal and B. M. Bhanage, Adv. Synth. Catal., 2015, 357, 883-900.

22 S. Werkmeister, K. Junge and M. Beller, Org. Process Res. Dev., 2014, 18, 289-302.

23 G. A. Filonenko, R. van Putten, E. J. M. Hensen and E. A. Pidko, Chem. Soc. Rev., 2018, 47, 1459-1483.

24 L. Alig, M. Fritz and S. Schneider, Chem. Rev., 2019, 119, 2681-2751.

25 T. vom Stein, M. Meuresch, D. Limper, M. Schmitz, M. Holscher, J. Coetzee, D. J. Cole-Hamilton, J. Klankermayer and W. Leitner, J. Am. Chem. Soc., 2014, 136, 13217-13225.

26 X. Cui, Y. Li, C. Topf, K. Junge and M. Beller, Angew. Chem., Int. Ed., 2015, 54, 10596-10599.

27 Y. Li, C. Topf, X. Cui, K. Junge and M. Beller, Angew. Chem., Int. Ed., 2015, 54, 5196-5200.

28 I. Mellone, F. Bertini, L. Gonsalvi, A. Guerriero and M. Peruzzini, Chimia, 2015, 69, 331-338.

29 J. R. Cabrero-Antonino, E. Alberico, K. Junge, H. Junge and M. Beller, Chem. Sci., 2016, 7, 3432-3442.

30 T. Suarez and B. Fontal, J. Mol. Catal., 1988, 45, 335-344.

31 R. Adam, C. B. Bheeter, R. Jackstell and M. Beller, ChemCatChem, 2016, 8, 1329-1334.

32 R. Adam, C. B. Bheeter, J. R. Cabrero-Antonino, K. Junge, R. Jackstell and M. Beller, ChemSusChem, 2017, 10, 842-846.

33 C. Bianchini, V. Dal Santo, A. Meli, W. Oberhauser, R. Psaro and F. Vizza, Organometallics, 2000, 19, 2433-2444.

34 C. Bianchini, M. Frediani and F. Vizza, Chem. Commun., 2001, 479-480.

35 D. J. Cole-Hamilton, Science, 2003, 299, 1702-1706.

36 N. E. Leadbeater and M. Marco, Chem. Rev., 2002, 102, 32173274 .

37 D. E. Bergbreiter, Chem. Rev., 2002, 102, 3345-3384.
38 R. van Heerbeek, P. C. J. Kamer, P. W. N. M. van Leeuwen and J. N. H. Reek, Chem. Rev., 2002, 102, 3717-3756.

39 D. J. Cole-Hamilton and R. P. Tooze, in Catalyst Separation, Recovery and Recycling: Chemistry and Process Design, ed. D. J. Cole-Hamilton and R. P. Tooze, Springer Netherlands, Dordrecht, 2006, pp. 1-8.

40 P. J. C. Hausoul, C. Broicher, R. Vegliante, C. Göb and R. Palkovits, Angew. Chem., Int. Ed., 2016, 55, 5597-5601.

41 P. C. J. Kamer, D. Vogt and J. W. Thybaut, Contemporary Catalysis: Science, Technology, and Applications, The Royal Society of Chemistry, 2017.

42 R. A. Findeis and L. H. Gade, Eur. J. Inorg. Chem., 2003, 2003, 99-110.

43 L. Harmand, S. Samer, J. Andrieu, H. Cattey, M. Picquet and J.-C. Hierso, Open Org. Chem. J., 2012, 6, 1-11.

44 C. Bianchini, A. Meli, V. Patinec, V. Sernau and F. Vizza, J. Am. Chem. Soc., 1997, 119, 4945-4954.

45 I. Rojas, F. L. Linares, N. Valencia and C. Bianchini, J. Mol. Catal. A: Chem., 1999, 144, 1-6.

46 C. Bianchini, A. Meli and W. Oberhauser, New J. Chem., 2001, 25, 11-12.

47 P. Schober, G. Huttner, L. Zsolnai and A. Jacobi, J. Organomet. Chem., 1998, 571, 279-288.

48 R. A. Findeis and L. H. Gade, Dalton Trans., 2003, 249-254.

49 W. Hewertson and H. R. Watson, J. Chem. Soc., 1962, 14901494.

50 H. Heidel, G. Huttner and G. Helmchen, Z. Naturforschung B, 1993, 48, 1681-1692.

51 L. Söncksen, C. Gradert, J. Krahmer, C. Näther and F. Tuczek, Inorg. Chem., 2013, 52, 6576-6589.

52 N. Nakagawa, E. J. Derrah, M. Schelwies, F. Rominger, O. Trapp and T. Schaub, Dalton Trans., 2016, 45, 6856-6865.

53 D. Obrecht and J. M. Villalgordo, in Solid-Supported Combinatorial and Parallel Synthesis of Small-MolecularWeight Compound Libraries, Elsevier Science ltd., Oxford, 1998, ch. 1, pp. 1-184.

54 K. Burgess, Solid-Phase Organic Synthesis, John Wiley \& Sons, Inc., New York, 2002.

55 M. C. Samuels, B. H. G. Swennenhuis and P. C. J. Kamer, in Phosphorus(III) Ligands in Homogeneous Catalysis: Design and Synthesis, ed. P. C. J. Kamer and P. W. N. M. v. Leeuwen, John Wiley \& Sons, Ltd, Chichester, 2012, ch. 16, pp. 463-479.

56 S. E. Booth, C. M. Dreef-Tromp, P. H. H. Hermkens, J. A. P. A. de Man and H. C. J. Ottenheijm, in Combinatorial Chemistry, ed. G. Jung, Wiley-VCH Verlag GmbH, Weinheim, 1999, ch. 2, pp. 35-76.

57 C. Gennari and U. Piarulli, Chem. Rev., 2003, 103, 3071-3100. 58 M. Renom-Carrasco and L. Lefort, Chem. Soc. Rev., 2018, 47, 5038-5060.

59 A. Kirschning, W. Solodenko and K. Mennecke, Chem.-Eur. J., 2006, 12, 5972-5990.

60 C. G. Frost and L. Mutton, Green Chem., 2010, 12, 1687-1703.

61 F. M. Akwi and P. Watts, Chem. Commun., 2018, 54, 1389413928.

62 A. Muth, O. Walter, G. Huttner, A. Asam, L. Zsolnai and C. Emmerich, J. Organomet. Chem., 1994, 468, 149-163. 
63 F. J. L. Heutz, M. C. Samuels and P. C. J. Kamer, Catal. Sci. Technol., 2015, 5, 3296-3301.

64 M. C. Samuels, F. J. L. Heutz, A. Grabulosa and P. C. J. Kamer, Top. Catal., 2016, 59, 1793-1799.

65 T. T. Adint and C. R. Landis, J. Am. Chem. Soc., 2014, 136, 7943-7953.

66 X. Wang, E. A. P. Ling, C. Guan, Q. Zhang, W. Wu, P. Liu, N. Zheng, D. Zhang, S. Lopatin, Z. Lai and K.-W. Huang, ChemSusChem, 2018, 11, 3591-3598.
67 S. Enthaler, D. Addis, K. Junge, G. Erre and M. Beller, Chem.Eur. J., 2008, 14, 9491-9494.

68 S. Enthaler, K. Junge, D. Addis, G. Erre and M. Beller, ChemSusChem, 2008, 1, 1006-1010.

69 I. G. Molnár, P. Calleja, M. Ernst, A. S. K. Hashmi and T. Schaub, ChemCatChem, 2017, 9, 4175-4178.

70 A. J. M. van Dijk, R. Duchateau, E. J. M. Hensen, J. Meuldijk and C. E. Koning, Chem.-Eur. J., 2007, 13, 7673-7681. 